\title{
Retired Plastic Surgeons as Educators During the COVID-19 Pandemic
}

\author{
Sammy Al-Benna ${ }^{1}$
}

Received: 9 September 2020/ Accepted: 10 September 2020/Published online: 21 September 2020

(C) Springer Science+Business Media, LLC, part of Springer Nature and International Society of Aesthetic Plastic Surgery 2020

Level of Evidence $V$ This journal requires that authors assign a level of evidence to each article. For a full description of these Evidence-Based Medicine ratings, please refer to the Table of Contents or the online Instructions to Authors www.springer.com/00266

There are an estimated 46,300 plastic surgeons worldwide [1]. More than one-third of all physicians are 65 or older [2]. At this very moment, there may be 15,000 retired plastic surgeons around the world. Our life's work and our identity as plastic surgeons deeply motivates our desire to help during this worldwide pandemic, yet we recognize that we are now considered a high-risk population [3-6]. It is during this time of wanting to contribute that inspired me to share this perspective [3-6].

In response to the COVID-19 pandemic, medical schools and universities have quickly switched the entire medical undergraduate and postgraduate surgical curriculums to online formats that include content in the basic sciences and health systems sciences [3, 4]. This undergraduate and postgraduate-oriented educational paradigm change requires online teaching and mentoring for medical students and surgical trainees, together with the creation of educational materials $[3,4]$. This process has inundated many surgical educators who have synchronous academic and clinical demands.

Retired plastic surgeons constitute a valuable and frequently underutilized resource for surgical training

Sammy Al-Benna

albenna@sun.ac.za

1 Division of Plastic and Reconstructive Surgery, Faculty of Medicine and Health Sciences, Stellenbosch University and Tygerberg Academic Hospital, Francie van Zijl Drive, Tygerberg, PO Box 241, Cape Town 8000, South Africa programs. Heads of Divisions of Plastic Surgery should explore opportunities to integrate retired surgical colleagues into their educational programs. Retired plastic surgeons, within their skills and knowledge, can provide online teaching, education materials and mentoring for medical students and plastic surgical trainees.

Retired plastic surgeons have extensive clinical experience, pattern-recognition skills, and reasoning abilities and can therefore share the wisdom and lessons learned during their careers in surgery with younger colleagues [7, 8]. In particular, over the course of their careers, retired plastic surgeons have developed the emotional intelligence that enables them to teach trainees valuable strategies for COVID-19 stress by remaining composed [7, 8]. With encouragement, these retired plastic surgeons can support a variety of virtual educational activities including multidisciplinary team oncology meeting, morbidity and mortality conferences, online simulation training, mock oral examinations, problem-based learning sessions for surgery residents and medical students and research projects.

Although retired plastic surgeons may not be able to participate clinically during the COVID-19 pandemic, they are a phenomenal resource for education. There is a universal need to engage our retired plastic surgeons. The COVID-19 pandemic may represent a unique opportunity for enduring transformation in surgical training, and incorporation of retired surgeons as voluntary faculty members in the plastic surgery department will benefit medical students, trainee surgeons, specialists, faculty, and retired surgeons in a similar way. The COVID-19 pandemic has made us recognize how we are much more alike than we are different, and this is definitely true in surgery and surgical education [9]. 
Funding None.

\section{Compliance with Ethical Standards}

Conflict of interest The authors declare that they have no conflict of interest

Human or Animal Rights This article does not contain any studies with human participants or animals performed by any of the authors.

Informed Consent For this type of study informed consent is not required.

\section{References}

1. International Society of Aesthetic Plastic Surgery ISAPS International Survey on Aesthetic/Cosmetic Procedures performed in (2018). Available at: https://www.isaps.org/wp-content/uploads/ 2019/12/ISAPS-Global-Survey-Results-2018-new.pdf. Accessed 9 Sep 2020

2. Association of American Medical Colleges (2019) Update the complexities of physician supply and demand: projections from 2017-2032. https://www.aamc.org/system/files/c/2/31-2019_ update_-_the_complexities_of_physician_supply_and_demand_-_ projections_from_2017-2032.pdf. Accessed 9 Sep 2020
3. Al-Benna S (2020) Concepts of management of plastic surgery services during the coronavirus disease 2019 pandemic. Eur J Plast Surg 13:1-2

4. Al-Benna S (2020) Impact of COVID-19 on surgical registrars' education and training. S Afr J Surg 58:10-13

5. Al-Benna S (2020) Availability of COVID-19 information from national and international aesthetic surgery society websites. Aesthet Plast Surg 44:1043-1046

6. Al-Benna S, Gohritz A (2020) Availability of COVID-19 information From national plastic surgery society web sites. Ann Plast Surg 85:S171-S172

7. Al-Benna $S$ (2014) The paradigm of burn expertise: scientia est lux lucis. Burns 40:1235-1239

8. Al-Benna S, O'Boyle C (2014) Burn care experts and burn expertise. Burns 40:200-203

9. Al-Benna S (2020) Sword of damocles: application of the ethical principles of resource allocation to essential cancer surgery patients requiring beds in limited supply during the COVID-19 pandemic. Eur Surg 7:1-2. https://doi.org/10.1007/s10353-02000655 -

Publisher's Note Springer Nature remains neutral with regard to jurisdictional claims in published maps and institutional affiliations. 